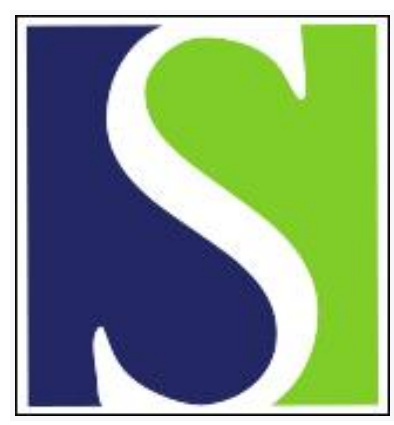

Scand J Work Environ Health 1997;23(2):121-129

https://doi.org/10.5271/sjweh.189

Issue date: Apr 1997

Sickness absence from back pain, psychosocial work characteristics and employment grade among office workers

by Hemingway $\mathrm{H}$, Shipley MJ, Stansfeld S, Marmot M

The following articles refer to this text: 2001;27(4):258-267;

2004;30(4):261-278; 2009;35(2):85-95

Key terms: cohort study; etiology; MSD; musculoskeletal disorder; prospective study; socioeconomic status

This article in PubMed: www.ncbi.nlm.nih.gov/pubmed/9167235

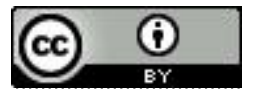




\title{
Sickness absence from back pain, psychosocial work characteristics and employment grade among office workers
}

\author{
by Harry Hemingway, MRCP, Martin J Shipley, Msc, ${ }^{1}$ Stephen Stansfeld, PhD, ${ }^{2}$ \\ Michael Marmot, FFPHM ${ }^{2}$
}

\begin{abstract}
Hemingway $H$, Shipley MJ, Stansfeld S, Marmot M. Sickness absence from back pain, psychosocial work characteristics and employment grade among office workers. Scand $J$ Work Environ Health 1997;23(2):121-9.

Objectives The relation between psychosocial work characteristics, employment grade, and sickness absence due to back pain was studied among office workers.

Methods Base-line questionnaire data and sickness absence data collected continuously with a mean of 4 years of follow-up were analyzed. The subjects were 6894 men and 3414 women aged 35 to 55 years at recruitment. The main outcome measures were short ( $\leq 7$ days) and long ( $>7$ days) absences due to back pain.

Results There was a strong inverse association between employment grade and rate of absences due to back pain ( $\mathbf{P}$ for linear trend $<0.001$ ); for example, the rate ratio for short absences among the men in a comparison of lowest versus highest employment grade was 8.21. The age adjusted rate ratio for the effect of low versus high control over work among the men was 2.22 [95\% confidence interval $(95 \% \mathrm{CI}) 1.77-2.79$ ] for short and 1.61 (95\% CI 1.01-2.58) for long absences due to back pain. For short absences due to back pain among the men in high grades of employment, the rate ratio for low control was 3.42 compared with 0.78 for the lower grades (P for interaction $<0.001)$. For the women the corresponding rate ratios were 0.80 and 1.35 , respectively ( $\mathrm{P}$ for interaction 0.08 )

Conclusions Absence from work due to back pain was strongly inversely related to employment grade. The effects of psychosocial work characteristics - particularly control - differed by grade and gender in magnitude and direction. The psychosocial work environment represents a potentially reversible cause of ill health.
\end{abstract}

Key terms cohort study, etiology, musculoskeletal disorders, prospective study, socioeconomic status.

Data from countries with different health and welfare provision suggest an epidemic of disability associated with back pain. Population prevalence $(1,2)$, primary (3-6) and secondary (7) care consultation rates, sickness absence $(8,9)$, and compensation claims for back pain all show a rising trend. Back pain is the most common cause of disability for work populations (10), and there is growing recognition that absence due to back pain is the best measure of such disability (11). The costs associated with lost production due to back pain in the United Kingdom in 1993 have been estimated at GBP 3.8 billion, and the costs of social security benefits have been estimated at GBP 1.4 billion (7).

The etiology of back pain is poorly understood (12). Most studies have concentrated on physical risk factors (such as lifting, twisting and bending) in manual occupations (13), yet it has been estimated that only $20 \%$ of all back pain can be attributed to such exposures (14). The majority of people with back pain have no recognizable pathological lesion (15); magnetic resonance imaging has not demonstrated anatomical differences in those with and without back pain (16). Increasingly people work in sedentary office jobs (17) although very few studies have examined back pain among office workers (18). The evidence for an association between prolonged sitting postures and back pain is conflicting (19).

Socioeconomic status is inversely associated with most causes of morbidity and mortality; yet there have been comparatively few reports focusing on associations with back pain $(20,21)$. Existing studies have tended to use socioeconomic status as a measure of occupational physical exposure, noting large differences between manual and nonmanual occupations. Psychosocial work characteristics, which are strongly associated with socioeco-

1 Department of Public Health, Kensington \& Chelsea and Westminster Health Authority, London, United Kingdom.

2 Department of Epidemiology and Public Health, University College London Medical School, London, United Kingdom.

Reprint request to: Harry Hemingway, Department of Public Health, Kensington \& Chelsea and Westminster Health Authority, 50 Eastbourne Terrace, London W2 6LX, United Kingdom (e-mail: h.hemingway@ public-health.ucl.ac.uk). 
nomic status, have been proposed as mediators of the relation between socioeconomic status and health (22).

A 3-year longitudinal study of 3020 aircraft employees found that subjects who "hardly ever" enjoyed their job tasks were 2.5 times more likely to report a back injury than those who almost always enjoyed their tasks (23). A recent review recommended examination of the effect of low control over work and high qualitative and quantitative job demands as more specific psychosocial work characteristics that may be involved in the etiology of back pain (24). The objective therefore was to examine the relationship between psychosocial work characteristics, employment grade, and sickness absence due to back pain in the Whitehall II study of British nonindustrial civil servants (25).

\section{Subjects and methods}

\section{Study population}

All nonindustrial civil servants aged $35-55$ years and working in the London offices of 20 departments were invited to participate in the study. The overall response rate was $73 \%$, although the true response rate was likely to be higher because around $4 \%$ of those on the list of employees had, in fact, moved before the study and were thus not eligible for inclusion. Altogether 10308 civil servants participated, of whom 67\% $(\mathrm{N}=6894)$ were men and $33 \%(\mathrm{~N}=3414)$ were women.

\section{Base-line survey}

Between November 1985 and March 1988 the participants completed a questionnaire and attended a screening examination. The questionnaire included 3 questions on back pain (in the last 14 days, in the last 12 months and as a longstanding illness) (26). In addition the questionnaire included details on socioeconomic status (current civil service employment grade, years of full-time education, housing tenure, access to the use of car or van), health-related behavior (smoking habits, exercise), and psychosocial work characteristics. On the basis of salary the civil service identifies 12 nonindustrial grades. To obtain significant numbers, we combined the top 6 grades into grade 1 and the bottom 2 grades into grade 6 , thus producing 6 grade categories: unified grades (UG) 1-6, unified grade 7, senior executive officer (SEO), higher executive officer (HEO), executive officer $(E O)$, and clerical and support grades. Psychosocial work characteristics were assessed with a 67-item questionnaire based on the occupational strain model of job demands and decision latitude (27). A principal components analysis supported the following dimensions: control over work (8 items), conflicting demands ( 2 items), pace ( 3 items), social support at work (6 items), and job satisfaction ( 8 items). Height and weight were recorded, and body mass index was calculated as weight $(\mathrm{kg}) /$ height $(\mathrm{m})^{2}$.

\section{Follow-up and sickness absence}

Most of the participants ( $94 \%$ ) gave their consent for a follow-up based on their sick leave records. These records included the first and last dates of all absences to the end of 1990 and, for 14 out of the 20 departments, the reason for the absence. Data on the reasons for absence were therefore available for $61 \%(\mathrm{~N}=5620)$ of the participants in connection with their sick leave records. For absences of 7 days or fewer (short spells), civil servants were able explain their absence on their certificate. For absences of more than 7 calendar days (long spells), a medical certificate from a general practitioner was required.

The reasons for absence were coded from these certificates by the civil service according to the 8th revision of the International Classification of Diseases. The following civil service codes were included: disc, intervertebral (displaced, lesion, prolapsed, slipped); disc, pain; sciatica; pain, legs; back pain; backache; pain, low back (muscular, rheumatic); lumbago; lumbar strain. One hundred and thirty-two participants reporting possible or probable intermittent claudication (28) were excluded from all the analyses to avoid the possibility of misdiagnosis as sciatica. A comparison of stated reasons for absence and the diagnosis of the general practitioner in spells lasting more than 21 days showed disagreement for 12 of 65 participants when the general practitioner provided only 1 reason for absence and disagreement for 1 of 20 participants when the general practitioner provided more than 1 reason for absence (unpublished results of Anderssen et al).

\section{Statistical analysis}

For each psychosocial work characteristic, an index was created by summing question scores and dividing each score into tertiles. Short ( $\leq 7$ days) and long ( $>7$ days) sickness absences were analyzed separately. For each employee, the number of absences of each type was computed, and the follow-up was calculated in personyears. Rates of sickness absence were expressed per 100 person-years. Age-adjusted rates were calculated by direct standardization using the total study population as the standard. The number of sickness absences is a form of count data and therefore Poisson regression models were used to calculate adjusted rate ratios and their $95 \%$ confidence intervals ( $95 \%$ CI). Details of the method used have been reported previously (29). For short absences for all reasons, there was considerable residual variation in the excess of the Poisson distribution (overdispersion). Estimates of the $95 \%$ confidence intervals 
were adjusted for this overdispersion. The analyses were carried out with the statistical package GLIM (general linear interactive modeling) (30).

Adjustment for employment grade risks overadjustment since the exposures of interest - psychosocial work characteristics - are so strongly related to grade. Therefore adjustment was made for socioeconomic measures other than grade (education, car access, housing tenure). To assess the effect modification, within-grade analyses were performed using 3 levels of grade (men) and 2 levels of grade (women) for short spells of absence. There were too few long spells to permit stratification. All the fully adjusted models included age, nongrade measures of socioeconomic status (education, car access, housing tenure), number of self-reports of back pain at the beginning of the study, body mass index (in gender-specific quartiles), exercise (none or mild versus moderate or vigorous), and smoking habits. These factors have been associated with back pain in other studies (13) and were included in the models on a priori grounds. Individuals with incomplete data were excluded from the analyses involving these values.

\section{Results}

In the beginning of the study, the age-standardized 12month period prevalence of self-reported "sciatica, lumbago or recurring backache" was $21 \%$ for the men and $27 \%$ for the women. Seventy-seven percent of all spells of sickness absence due to back pain were single (nonrecurrent).

Table 1 shows that there were marked inverse gradients for age-adjusted absences due to back pain by civil service employment grade (test for linear trend $\mathrm{P}<0.001$ for both short and long absences among both the men and the women). The rate ratios comparing the lowest versus highest employment grade for short and long sickness absences were 8.21 and 7.14 for the men and 28.05 and 7.15 for the women, respectively (although it should be noted that there was only 1 spell of short and 1 spell of long absence for the women in the highest grade). Excluding the participants who had reported any back pain at the beginning of the study made little difference to these relationships.

The number of positive answers to the 3 different self-reports of back pain at the beginning of the study showed a strong, stepwise relationship to subsequent absence due to back pain. This relationship was found for both the short and long spells of the men and women (test for linear trend $\mathrm{P}<0.001$ for each). The relation for long spells is shown in figure 1 . The number of selfreports of back pain showed no relation with the psychosocial work characteristics, with the exception that high job satisfaction was associated with fewer reports of back pain (test for heterogeneity $\mathrm{P}=0.006$ ).

Table 2 shows the effect of psychosocial work characteristics on short absences due to back pain among the men. In age-adjusted models only conflicting demands failed to show an effect. The age-adjusted rate ratio (RR) for the effect of low versus high control over work was 2.22 (95\% CI 1.77-2.79) for short spells among the men (for simplicity, rate ratios in the text refer to a

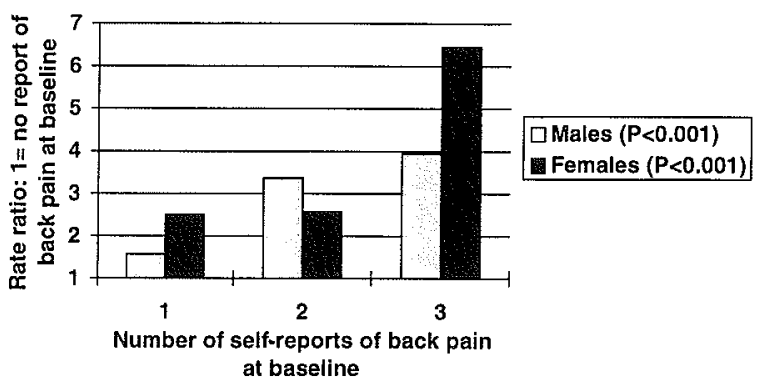

Figure 1. Age-adjusted rate ratios of long absences from work because of back pain by number of positive responses to three self-report questions on back pain (in last 14 days, in last 12 months, long-term illness).

Table 1. Rates and number of absences due to back pain by grade, gender, and length of absence.

\begin{tabular}{|c|c|c|c|c|c|c|c|c|}
\hline \multirow[t]{3}{*}{ Grade } & \multicolumn{4}{|c|}{ Men } & \multicolumn{4}{|c|}{ Women } \\
\hline & \multicolumn{2}{|c|}{$\begin{array}{l}\text { Short sickness absences } \\
\qquad(\leq 7 \mathrm{~d})\end{array}$} & \multicolumn{2}{|c|}{$\begin{array}{l}\text { Long sickness absences } \\
\qquad(>7 d)\end{array}$} & \multicolumn{2}{|c|}{$\begin{array}{l}\text { Short sickness absences } \\
\qquad(\leq 7 \mathrm{~d})\end{array}$} & \multicolumn{2}{|c|}{$\begin{array}{l}\text { Long sickness absences } \\
\qquad(>7 \mathrm{~d})\end{array}$} \\
\hline & Rate & N & Rate & $\mathbf{N}$ & Rate & N & Rate & $\mathrm{N}$ \\
\hline $\begin{array}{l}1 \text { (high) } \\
2 \\
3 \\
4 \\
5 \\
6 \text { (low) }\end{array}$ & $\begin{array}{c}1.34 \\
2.92 \\
2.26 \\
4.15 \\
11.16 \\
11.00^{\star}\end{array}$ & $\begin{array}{r}36 \\
96 \\
52 \\
115 \\
172 \\
99\end{array}$ & $\begin{array}{l}0.37 \\
0.82 \\
0.84 \\
1.12 \\
1.65 \\
2.64^{*}\end{array}$ & $\begin{array}{r}9 \\
27 \\
20 \\
35 \\
26 \\
23\end{array}$ & $\begin{array}{c}0.40 \\
0.38 \\
2.35 \\
4.09 \\
6.86 \\
11.22^{*}\end{array}$ & $\begin{array}{r}1 \\
2 \\
9 \\
37 \\
82 \\
271\end{array}$ & $\begin{array}{l}0.40 \\
0.40 \\
0.18 \\
1.35 \\
1.48 \\
2.86^{*}\end{array}$ & $\begin{array}{r}1 \\
2 \\
1 \\
12 \\
19 \\
106\end{array}$ \\
\hline Total & 4.27 & 570 & 1.05 & 140 & 6.81 & 402 & 1.78 & 106 \\
\hline
\end{tabular}

a Rates per 100 person-years, age standardized.

* $P$ for linear trend $<0.001$. 
Table 2. Rate ratios (RR) of short absences due to back pain by psychosocial work characteristics among the men. (HEO = higher executive officer, $\mathrm{SEO}=$ senior executive officer, EO = executive officer, $95 \% \mathrm{Cl}=95 \%$ confidence interval)

\begin{tabular}{|c|c|c|c|c|c|c|c|c|c|c|}
\hline \multirow{3}{*}{$\begin{array}{l}\text { Psychosocial work } \\
\text { characteristic }\end{array}$} & \multicolumn{4}{|c|}{ All grades } & \multicolumn{6}{|c|}{ Within grades } \\
\hline & \multicolumn{2}{|c|}{ Age-adjusted } & \multicolumn{2}{|c|}{ Fully adjusted ${ }^{b}$} & \multicolumn{2}{|c|}{$\begin{array}{l}\text { Unified grade1- } \\
\text { unified grade } 7\end{array}$} & \multicolumn{2}{|c|}{ HEO/SEO/EO } & \multicolumn{2}{|c|}{ Clerical support } \\
\hline & $R R$ & $95 \% \mathrm{Cl}$ & $\mathrm{RR}$ & $95 \% \mathrm{Cl}$ & $\mathrm{RR}$ & Spells & $\mathrm{RR}$ & Spefls & $\mathrm{RR}$ & Spells \\
\hline \multicolumn{11}{|l|}{ Control } \\
\hline $\begin{array}{l}\text { High } \\
\text { Medium } \\
\text { Low }\end{array}$ & $\begin{array}{l}1.0 \\
1.70 \\
2.22\end{array}$ & $\begin{array}{l}1.37-2.11 \\
1.77-2.79\end{array}$ & $\begin{array}{l}1.00 \\
1.31 \\
1.44\end{array}$ & $\begin{array}{l}1.04-1.64 \\
1.11-1.85\end{array}$ & $\begin{array}{r}1.00 \\
2.85 \\
3.42 \\
\text { Test for }\end{array}$ & $\begin{array}{c}34 \\
58 \\
26 \\
\text { nteractior }\end{array}$ & $\begin{array}{l}1.0 \\
1.17 \\
1.26 \\
(4 \mathrm{df})=\end{array}$ & $\begin{array}{r}91 \\
124 \\
82 \\
22.69(\mathrm{~F}\end{array}$ & $\begin{array}{c}1.0 \\
0.55 \\
0.78 \\
.001)\end{array}$ & $\begin{array}{l}16 \\
11 \\
48\end{array}$ \\
\hline Conflict & & & & & & & & & & \\
\hline $\begin{array}{l}\text { High } \\
\text { Medium } \\
\text { Low }\end{array}$ & $\begin{array}{l}1.00 \\
1.02 \\
1.01\end{array}$ & $\begin{array}{l}0.83-1.25 \\
0.79-1.30\end{array}$ & $\begin{array}{l}1.00 \\
0.88 \\
0.73\end{array}$ & $\begin{array}{l}0.71-1.09 \\
0.55-0.95\end{array}$ & $\begin{array}{c}1.0 \\
1.06 \\
1.04 \\
\text { Test for }\end{array}$ & $\begin{array}{c}38 \\
55 \\
25 \\
\text { nteraction }\end{array}$ & $\begin{array}{l}1.0 \\
0.94 \\
1.12 \\
(4 \mathrm{df})\end{array}$ & $\begin{array}{r}90 \\
139 \\
68 \\
8.14(\mathrm{P}\end{array}$ & $\begin{array}{l}1.0 \\
0.78 \\
0.41\end{array}$ & $\begin{array}{l}23 \\
40 \\
12\end{array}$ \\
\hline Pace & & & & & & & & & & \\
\hline $\begin{array}{l}\text { High } \\
\text { Medium } \\
\text { Low }\end{array}$ & $\begin{array}{l}1.0 \\
1.34 \\
2.10\end{array}$ & $\begin{array}{c}. \\
1.06-1.69 \\
1.68-2.63\end{array}$ & $\begin{array}{l}1.0 \\
1.21 \\
1.79\end{array}$ & $\begin{array}{l}0.96-1.54 \\
1.39-2.31\end{array}$ & $\begin{array}{c}1.0 \\
1.92 \\
3.14 \\
\text { Test for }\end{array}$ & $\begin{array}{c}31 \\
41 \\
46 \\
\text { nteractior }\end{array}$ & $\begin{array}{c}1.0 \\
0.81 \\
1.52 \\
(4 \mathrm{df})\end{array}$ & $\begin{array}{r}85 \\
97 \\
115 \\
18.58(\mathrm{~F}\end{array}$ & $\begin{array}{c}1.0 \\
1.72 \\
1.53 \\
0.001)\end{array}$ & $\begin{array}{r}24 \\
30 \\
7\end{array}$ \\
\hline Work social support & & & & & & & & & & \\
\hline $\begin{array}{l}\text { High } \\
\text { Medium } \\
\text { Low }\end{array}$ & $\begin{array}{l}1.0 \\
1.14 \\
1.44\end{array}$ & $\begin{array}{l}0.91-1.43 \\
1.17-1.79\end{array}$ & $\begin{array}{l}1.0 \\
1.01 \\
1.12\end{array}$ & $\begin{array}{l}0.80-1.27 \\
0.89-1.41\end{array}$ & $\begin{array}{c}1.0 \\
1.27 \\
0.76 \\
\text { Test for }\end{array}$ & $\begin{array}{c}39 \\
52 \\
27 \\
\text { nteraction }\end{array}$ & $\begin{array}{c}1.0 \\
1.00 \\
1.28 \\
(4 \mathrm{df})\end{array}$ & $\begin{array}{r}94 \\
85 \\
118 \\
15.77(\mathrm{P}\end{array}$ & $\begin{array}{c}1.0 \\
1.40 \\
2.66 \\
0.01)\end{array}$ & $\begin{array}{l}11 \\
15 \\
49\end{array}$ \\
\hline Job satisfaction & & & & & & & & & & \\
\hline $\begin{array}{l}\text { High } \\
\text { Medium } \\
\text { Low }\end{array}$ & $\begin{array}{l}1.0 \\
1.29 \\
1.95\end{array}$ & $\begin{array}{l}1.01-1.66 \\
1.58-2.40\end{array}$ & $\begin{array}{l}1.0 \\
1.04 \\
1.17\end{array}$ & $\begin{array}{l}0.80-1.33 \\
0.92-1.48\end{array}$ & $\begin{array}{c}1.0 \\
1.67 \\
2.33 \\
\text { Test for }\end{array}$ & $\begin{array}{c}37 \\
33 \\
48 \\
\text { nteractior }\end{array}$ & $\begin{array}{c}1.0 \\
0.80 \\
0.90 \\
(4 \mathrm{df})\end{array}$ & $\begin{array}{r}95 \\
65 \\
137 \\
22.08(\mathrm{~F}\end{array}$ & $\begin{array}{c}1.0 \\
1.90 \\
2.89 \\
0.001)\end{array}$ & $\begin{array}{l}10 \\
16 \\
49\end{array}$ \\
\hline
\end{tabular}

a Adjusted for age and confounders only.

b Full adjustment: age, confounders (education, housing tenure, access to use of car, body mass index, exercise, smoking habits, and the number of questionnaire reports of back pain at the beginning of the study), and other psychosocial work characteristics.

comparison between low and high tertiles of each psychosocial work characteristic). Full adjustment for the other psychosocial work characteristics and confounders (education, car access and housing tenure, body mass index, exercise, smoking, and the number of reports of back pain at the beginning of the study) showed independent effects of low control (RR 1.44, 95\% CI 1.111.85), low pace (RR $1.7995 \%$ CI $1.39-2.31$ ) and low conflicting demands (RR 0.73, 95\% CI 0.55-0.95). The within-grade analyses adjusting only for confounders showed significant interactions for each work characteristic except conflicting demands. The rate ratio for control was 3.42 in the top grades compared with 0.78 in the lowest grades ( $\mathrm{P}$ for interaction $<0.001$ ).

Table 3 shows the effect of psychosocial work characteristics on short absences due to back pain among the women. In the age-adjusted models, only social support at work failed to show an effect. An independent effect of pace was found in the fully adjusted models with a rate ratio of 1.42 (95\% CI $0.98-2.07)$. The within-grade analyses adjusting for confounders showed some evidence of interaction for control and job satisfaction ( $\mathrm{P}$ for interaction 0.08). Among the higher grade stratum, low control was protective (RR 0.80), and among the lower grades it was a risk factor (RR 1.35). Full adjustment (ie, age + confounders + work characteristics) of the withingrade analyses made little difference to the estimates for the men or the women.

The effects of the psychosocial work characteristics on long absences due to back pain are shown in table 4. Only the age-adjusted effect of control among the men was statistically significant. Low control and low conflicting demands were associated consistently, although nonsignificantly, with elevated rate ratios.

Low job satisfaction was associated with an increase in short absences due to back pain, but this effect was virtually abolished in the fully adjusted models. However, omitting the adjustment for the number of selfreports of back pain at the beginning of the study from the fully adjusted model increased the effect of job satisfaction, with rate ratios (low versus high) of 1.34 (short absences) and 1.28 (long absences) for the men. The rate ratios for the women were 1.25 and 1.12 , respectively. Omitting this adjustment made little difference to the estimates for the other psychosocial work characteristics.

Table 5 shows the extent to which the risk factors predicted sickness absence from all causes (excluding back pain) separately from sickness absence due to back pain. Self-reported back pain at the beginning of the study showed little relationship to all causes (excluding 
Table 3. Rate ratios (RR) of short absences due to back pain by psychosocial work characteristics among the women. (HEO $=$ higher executive officer, $\mathrm{SEO}=$ senior executive officer, $\mathrm{EO}=$ executive officer, $95 \% \mathrm{CI}=95 \%$ confidence interval)

\begin{tabular}{|c|c|c|c|c|c|c|c|c|}
\hline \multirow{3}{*}{$\begin{array}{l}\text { Psychosocial work } \\
\text { characteristic }\end{array}$} & \multicolumn{4}{|c|}{ All grades } & \multicolumn{4}{|c|}{ Within grades ${ }^{a}$} \\
\hline & \multicolumn{2}{|c|}{ Age-adjusted } & \multicolumn{2}{|c|}{ Fully adjusted ${ }^{b}$} & \multicolumn{2}{|c|}{$\mathrm{HEO} / \mathrm{SEO} / \mathrm{EO}$} & \multicolumn{2}{|c|}{ Clerical support } \\
\hline & RR & $95 \% \mathrm{Cl}$ & $\mathrm{RR}$ & $95 \% \mathrm{Cl}$ & $\mathrm{RR}$ & Spells & RR & Spells \\
\hline \multicolumn{9}{|l|}{ Control } \\
\hline $\begin{array}{l}\text { High } \\
\text { Medium } \\
\text { Low }\end{array}$ & $\begin{array}{l}1.0 \\
1.20 \\
1.47\end{array}$ & $\begin{array}{l}0.83-1.73 \\
1.04-2.05\end{array}$ & $\begin{array}{l}1.0 \\
1.04 \\
1.01\end{array}$ & $\begin{array}{l}0.71-1.53 \\
0.70-1.47\end{array}$ & $\begin{array}{r}1.0 \\
0.67 \\
0.80 \\
\text { Test for ii }\end{array}$ & $\begin{array}{c}33 \\
25 \\
32 \\
\text { action, > }\end{array}$ & $\begin{array}{l}1.0 \\
1.65 \\
1.35 \\
=5.04\end{array}$ & $\begin{aligned} & 12 \\
& 48 \\
& 106 \\
&=0.08)\end{aligned}$ \\
\hline Conflict & & & & & \multicolumn{4}{|c|}{ Test for interaction, $X^{2}(2 \mathrm{df})=5.04(P=0.08)$} \\
\hline $\begin{array}{l}\text { High } \\
\text { Medium } \\
\text { Low }\end{array}$ & $\begin{array}{l}1.0 \\
1.31 \\
1.61\end{array}$ & $\begin{array}{l}0.90-1.91 \\
1.12-2.33\end{array}$ & $\begin{array}{l}1.0 \\
1.17 \\
1.30\end{array}$ & $\begin{array}{l}0.80-1.73 \\
0.87-1.94\end{array}$ & $\begin{array}{c}1.0 \\
0.78 \\
0.94 \\
\text { Test for ir }\end{array}$ & $\begin{array}{c}27 \\
37 \\
26 \\
\text { action, }>\end{array}$ & $\begin{array}{l}1.0 \\
1.74 \\
1.79 \\
=3.86\end{array}$ & $\begin{aligned} & 11 \\
& 63 \\
& 92 \\
= & 0.15)\end{aligned}$ \\
\hline Pace & & & & & & & & \\
\hline $\begin{array}{l}\text { High } \\
\text { Medium } \\
\text { Low }\end{array}$ & $\begin{array}{l}1.0 \\
1.63 \\
1.78\end{array}$ & $\begin{array}{l}1.15-2.30 \\
1.26-2.51\end{array}$ & $\begin{array}{l}1.0 \\
1.50 \\
1.42\end{array}$ & $\begin{array}{l}1.05-2.15 \\
0.98-2.07\end{array}$ & $\begin{array}{c}1.0 \\
1.50 \\
2.02 \\
\text { Test for ir }\end{array}$ & $\begin{array}{c}20 \\
38 \\
32 \\
\text { action, }>\end{array}$ & $\begin{array}{l}1.0 \\
1.37 \\
1.17 \\
=3.14\end{array}$ & $\begin{aligned} & 25 \\
& 66 \\
& 75 \\
= & 0.21)\end{aligned}$ \\
\hline $\begin{array}{l}\text { Work social support } \\
\text { High } \\
\text { Medium } \\
\text { Low }\end{array}$ & $\begin{array}{l}1.0 \\
0.87 \\
1.08\end{array}$ & $\begin{array}{l}0.63-1.20 \\
0.81-1.43\end{array}$ & $\begin{array}{l}1.0 \\
0.81 \\
0.87\end{array}$ & $\begin{array}{l}0.58-1.14 \\
0.63-1.19\end{array}$ & $\begin{array}{c}1.0 \\
0.67 \\
1.13 \\
\text { Test for in }\end{array}$ & $\begin{array}{c}28 \\
19 \\
43 \\
\text { action, }>\end{array}$ & $\begin{array}{l}1.0 \\
1.03 \\
0.91 \\
=3.76\end{array}$ & $\begin{array}{c}53 \\
46 \\
57 \\
=0.15)\end{array}$ \\
\hline Job satisfaction & & & & & \multicolumn{4}{|c|}{ Test for interaction, $X^{2}(2 \mathrm{df})=3.76(P=0.15)$} \\
\hline $\begin{array}{l}\text { High } \\
\text { Medium } \\
\text { Low }\end{array}$ & $\begin{array}{l}1.0 \\
1.13 \\
1.34\end{array}$ & $\begin{array}{l}0.82-1.54 \\
1.01-1.78\end{array}$ & $\begin{array}{l}1.0 \\
1.08 \\
1.15\end{array}$ & $\begin{array}{l}0.78-1.50 \\
0.83-1.58\end{array}$ & $\begin{array}{c}1.0 \\
1.65 \\
1.97 \\
\text { Test for in }\end{array}$ & $\begin{array}{c}24 \\
26 \\
40 \\
\text { action, } X\end{array}$ & $\begin{array}{l}1.0 \\
0.93 \\
1.00 \\
=5.15\end{array}$ & $\begin{array}{c}84 \\
36 \\
46 \\
=0.08)\end{array}$ \\
\hline
\end{tabular}

adjusted for age and confounders only.

b Full adjustment: age, confounders (education, housing tenure, access to use of car, body mass index, exercise, smoking habits, and the number of questionnaire reports of back pain at the beginning of the study), and other psychosocial work characteristics.

Table 4. Rate ratios (RR) for long absences due to back pain by psychosocial work characteristics. ( $95 \% \mathrm{Cl}=95 \%$ confidence interval)

\begin{tabular}{|c|c|c|c|c|c|c|c|c|}
\hline \multirow{3}{*}{$\begin{array}{l}\text { Psychosocial work } \\
\text { characteristic }\end{array}$} & \multicolumn{4}{|c|}{ Men ( $N=112$ absences $)$} & \multicolumn{4}{|c|}{ Women ( $N=56$ absences) } \\
\hline & \multicolumn{2}{|c|}{ Age-adjusted } & \multicolumn{2}{|c|}{ Fully adjusted ${ }^{a}$} & \multicolumn{2}{|c|}{ Age-adjusted } & \multicolumn{2}{|c|}{ Fully adjusted ${ }^{a}$} \\
\hline & $\mathrm{RR}$ & $95 \% \mathrm{Cl}$ & $\mathrm{RR}$ & $95 \% \mathrm{Cl}$ & $\mathrm{RR}$ & $95 \% \mathrm{Cl}$ & $\mathrm{RR}$ & $95 \% \mathrm{Cl}$ \\
\hline \multicolumn{9}{|l|}{ Control } \\
\hline $\begin{array}{l}\text { High } \\
\text { Medium } \\
\text { Low }\end{array}$ & $\begin{array}{l}1.0 \\
1.27 \\
1.61\end{array}$ & $\begin{array}{l}0.82-1.97 \\
1.01-2.58\end{array}$ & $\begin{array}{l}1.0 \\
1.12 \\
1.37\end{array}$ & $\begin{array}{l}0.71-1.76 \\
0.81-2.30\end{array}$ & $\begin{array}{l}1.0 \\
1.41 \\
1.92\end{array}$ & $\begin{array}{l}0.60-3.13 \\
0.89-4.14\end{array}$ & $\begin{array}{l}1.0 \\
1.30 \\
1.47\end{array}$ & $\begin{array}{c}0.53-3.21 \\
0.60-3.57\end{array}$ \\
\hline \multicolumn{9}{|l|}{ Conflict } \\
\hline $\begin{array}{l}\text { High } \\
\text { Medium } \\
\text { Low }\end{array}$ & $\begin{array}{l}1.0 \\
1.03 \\
1.58\end{array}$ & $\begin{array}{l}0.66-1.62 \\
0.97-2.58\end{array}$ & $\begin{array}{l}1.0 \\
1.05 \\
1.63\end{array}$ & $\begin{array}{l}0.66-1.67 \\
0.96-2.78\end{array}$ & $\begin{array}{l}1.0 \\
1.06 \\
1.45\end{array}$ & $\begin{array}{l}0.48-2.33 \\
0.68-3.07\end{array}$ & $\begin{array}{l}1.0 \\
1.15 \\
1.72\end{array}$ & $\begin{array}{l}0.51-2.60 \\
0.75-3.92\end{array}$ \\
\hline \multicolumn{9}{|l|}{ Pace } \\
\hline $\begin{array}{l}\text { High } \\
\text { Medium } \\
\text { Low }\end{array}$ & $\begin{array}{l}1.0 \\
1.53 \\
1.48\end{array}$ & $\begin{array}{l}0.97-2.41 \\
0.91-2.41\end{array}$ & $\begin{array}{l}1.0 \\
1.47 \\
1.31\end{array}$ & $\begin{array}{l}0.92-2.34 \\
0.76-2.25\end{array}$ & $\begin{array}{l}1.0 \\
1.40 \\
0.54\end{array}$ & $\begin{array}{l}0.76-2.61 \\
0.25-1.18\end{array}$ & $\begin{array}{l}1.0 \\
1.23 \\
0.39\end{array}$ & $\begin{array}{l}0.64-2.36 \\
0.17-0.90\end{array}$ \\
\hline \multicolumn{9}{|l|}{ Work social support } \\
\hline $\begin{array}{l}\text { High } \\
\text { Medium } \\
\text { Low }\end{array}$ & $\begin{array}{l}1.0 \\
1.17 \\
1.49\end{array}$ & $\begin{array}{l}0.73-1.89 \\
0.95-2.34\end{array}$ & $\begin{array}{l}1.0 \\
1.11 \\
1.39\end{array}$ & $\begin{array}{l}0.68-1.80 \\
0.86-2.25\end{array}$ & $\begin{array}{l}1.0 \\
0.99 \\
1.21\end{array}$ & $\begin{array}{l}0.49-2.00 \\
0.65-2.26\end{array}$ & $\begin{array}{l}1.0 \\
0.96 \\
0.97\end{array}$ & $\begin{array}{l}0.45-2.03 \\
0.48-1.96\end{array}$ \\
\hline \multicolumn{9}{|l|}{ Job satisfaction } \\
\hline $\begin{array}{l}\text { High } \\
\text { Medium } \\
\text { Low }\end{array}$ & $\begin{array}{l}1.0 \\
1.45 \\
1.50\end{array}$ & $\begin{array}{c}\cdot \\
0.90-2.35 \\
0.73-1.95\end{array}$ & $\begin{array}{l}1.0 \\
1.32 \\
1.19\end{array}$ & $\begin{array}{c}. \\
0.81-2.17 \\
0.73-1.95\end{array}$ & $\begin{array}{l}1.0 \\
0.85 \\
1.25\end{array}$ & $\begin{array}{l}0.42-1.71 \\
0.69-2.26\end{array}$ & $\begin{array}{l}1.0 \\
0.68 \\
1.08\end{array}$ & $\begin{array}{l}0.32-1.44 \\
0.54-2.16\end{array}$ \\
\hline
\end{tabular}

a Full adjustment: age, confounders (education, housing tenure, access to use of car, body mass index, exercise, smoking habits, and the number of questionnaire reports of back pain at the beginning of the study), and other psychosocial work characteristics. 
Table 5. Rate ratios $(\mathrm{RR})$ and $95 \%$ confidence intervals ( $95 \% \mathrm{Cl}$ ) for sickness absence due to all causes (excluding back causes) and due to back pain by selected risk factors for the men and women combined. The work characteristics were summarized in this table by separating the participants into 2 categories below and above the median.

\begin{tabular}{|c|c|c|c|c|c|c|c|}
\hline \multicolumn{4}{|c|}{ All causes (excluding back pain) } & \multicolumn{4}{|c|}{ Back pain } \\
\hline & $\begin{array}{l}\text { bsences } \\
7 \mathrm{~d})\end{array}$ & & $\begin{array}{l}\text { onsences } \\
\text { d) }\end{array}$ & & $\begin{array}{l}\text { bsences } \\
\text { (d) }\end{array}$ & & $\begin{array}{l}\text { osences } \\
\text { d) }\end{array}$ \\
\hline $\mathrm{RR}$ & $95 \% \mathrm{Cl}$ & $\mathrm{R} R$ & $95 \% \mathrm{Cl}$ & $\mathrm{RR}$ & $95 \% \mathrm{Cl}$ & $\mathrm{RR}$ & $95 \% \mathrm{Cl}$ \\
\hline
\end{tabular}

Number of back pain

self reports

\begin{tabular}{lllllllll}
0 & 1.0 & & 1.0 & & 1.0 & & 1.0 & \\
1 & 1.27 & $1.17-1.37$ & 1.24 & $1.11-1.39$ & 2.00 & $1.65-2.42$ & 1.90 & $1.29-2.81$ \\
2 & 1.11 & $1.01-1.23$ & 1.33 & $1.18-1.49$ & 3.27 & $2.74-3.91$ & 3.02 & $2.09-4.36$ \\
3 & 1.11 & $0.93-1.33$ & 1.32 & $1.02-1.66$ & 6.55 & $5.22-8.22$ & 4.63 & $2.75-7.82$ \\
$\begin{array}{l}\text { Control } \\
\quad \text { Low versus high }\end{array}$ & 1.59 & $1.50-1.69$ & 1.49 & $1.38-1.61$ & 1.76 & $1.54-2.01$ & 1.64 & $1.25-2.14$ \\
$\begin{array}{l}\text { Conflict } \\
\quad \text { Low versus high }\end{array}$ & 1.09 & $1.03-1.15$ & 1.14 & $1.06-1.23$ & 1.29 & $1.13-1.46$ & 1.15 & $0.89-1.49$ \\
\hline
\end{tabular}

a The rate ratios have been adjusted for age and gender.

back pain) for sickness absence. The psychosocial work characteristics showed similar effects for all causes of sickness absence (excluding back pain) and for sickness absence due to back pain.

\section{Discussion}

This is the first prospective study relating psychosocial work characteristics to sickness absence due to back pain among office workers. Despite the low exposure to physical risk factors in this largely "white collar" cohort, we have demonstrated a striking inverse gradient for sickness absence due to back pain across employment grades; as the hierarchy is ascended the rates of absence decrease. Of the psychosocial work characteristics studied, low control showed the most consistent effects, predicting short and long absences due to back pain.

Absence due to back pain not only represents a measure of back pain morbidity, but also, in a working population, one of disability due to back pain. The strong inverse relation between civil service employment grade (an occupational measure of socioeconomic status) and sickness absence due to back pain was seen not only for short spells of absence, but also for long spells of absence which required medical certification. Therefore it is unlikely to reflect an underrecording of sickness absence or an underdiagnosis of back pain among the high grades. Each of the psychosocial work characteristics was strongly related to civil service employment grade - those at the top reported greater control over work, conflicting demands, and pace (25). Therefore adjusting for employment grade would risk "overadjustment" by removing the effect of interest. Therefore we adjusted for other markers of socioeconomic status (education, car access, housing tenure).
The demonstration of statistical interaction between employment grade and psychosocial work characteristics in the effects on sickness absence due to back pain is a novel finding. General explanations for the interactions between work characteristics and grade in the effect on back pain absences include 1 or a combination of the following: (i) work characteristics may be measuring different constructs in different grades, (ii) work characteristics may be measuring the same construct with differing precision in different grades, (iii) the meaning and consequences of work characteristics may differ by grade. Explanations of interactions between specific work characteristics and grade on sickness absence due to back pain are in part speculative; further work is required to test possible explanations and specify hypotheses.

In this prospective study of office workers, low control was associated with sickness absence due to back pain. This effect persisted (except for short absences among the women) after adjustment for other psychosocial work characteristics, nongrade measures of socioeconomic status, and other a priori confounders (obesity, smoking, exercise and preexisting back pain). The effect of control was similar for short ( $\leq 7$ days) and long (>7 days) absences, although for long absences it ceased to be significant. Cross-sectional associations have been reported between control at work and back pain, but an extensive review found no prospective studies investigating this association (24)

However, the effect of low control was reversed among the lower grade men and higher grade women. The meaning of a self-report of high control among low grades can be questioned, and its unlikely to correlate highly with external assessments. Conversely, control may have more meaning in the higher grades and may better discriminate between different aspects of the psychosocial work environment in the higher grades. If those 
in low grades have less variation in control than those in high grades, the interaction between grade and control may partly be explained. However, the standard deviations of the control scores was in fact higher in the lower grades, and therefore discounted this potential explanation.

The mechanism by which control over work may influence back pain is not known. It is possible that control over work involves control over the physical work environment. But this possibility is unlikely to be more than a partial explanation of the results, as work control has been associated with other conditions, such as coronary heart disease $(27,31)$, which are not directly related to the physical work environment. Furthermore, the effect persisted after adjustment for job satisfaction, a variable which includes satisfaction with the physical work environment. Control over work may also affect self-perceived stress and stress-related symptoms (32, 33) (such as headache, abdominal pain, or insomnia), which in turn may moderate the relationship between mechanical load and back pain by enhancing the perception of symptoms or reducing the capacity to cope with them. Control may influence muscle tone, sympathetic activity, or adrenocortical activity (34).

Low quantitative demands, as assessed by work pace, were associated with an increased risk of absence due to back pain, particularly for short spells of absence. In other studies, time pressure and monotonous work have been associated with back pain in both manual and nonmanual occupations, although there are some conflicting data (35). Thus it is possible that high pace among British civil servants has a different meaning; it is associated with higher employment grade and may be an indicator of being "in demand" and doing more varied work; low pace among office workers may signify monotony. The effect was present in the within-grade analyses, but residual confounding by grade remained a possible explanation. Low qualitative demands, as assessed by conflict, tended to be associated, albeit nonsignificantly, with a higher risk for absences. Only for the fully adjusted short absences of the men did low conflict act in the direction hypothesized by the "job-strain" model of work stress (27). Low work support may encourage people to take leave for back pain rather than remain at work, although previous analyses in this cohort have not found this feature to be restricted to the lower grades $(36,37)$, except for psychiatric sickness leave of women (38).

Low job satisfaction was associated with back pain in the age-adjusted models only. This effect was partly confounded by the association of job satisfaction with preexisting back pain. This finding raises the possibility that back pain may affect the report of job satisfaction, rather than vice versa. The effects of the other work characteristics were not confounded by preexisting back pain. Moreover the reduction of the rate ratios for low job satisfaction for short absences after adjustment for the other work characteristics suggests that the association between job satisfaction - a global assessment of work characteristics - and back pain found in other studies (24) may be mediated through these more specific work characteristics.

Unmeasured physical and ergonomic exposures could confound the observed associations. However, the variation in such exposures in this wholly office-based cohort is unlikely to have been large; within strata of employment grade this variation is likely to be small. Case definition of back pain is problematic. Back pain based on reported symptoms is open to response bias which may also influence the reporting of work characteristics. If the observed associations between work characteristics and sickness absence were confounded by a tendency to complain, then it might be hypothesized that the relationships would be found for short absences which are self-certified, rather than for long absences, which seem to be more related to illness (39). This possibility was not observed.

The observation that symptoms of back pain predicted sickness absence due to back pain increases the likelihood that both case definitions are valid. Furthermore the specificity of this effect (ie, that back pain symptoms did not predict all-cause back pain) suggests discrete patterns of absence behavior. Results from the Whitehall II study suggest that low control may predict a range of health outcomes: coronary heart disease (31), all-cause sickness absence, sickness absence due to back pain. Since the psychosocial work environment can be modified (40), this finding represents a potentially reversible cause of ill health.

Sickness absence due to back pain was common in this cohort of office workers and was strongly and inversely associated with socioeconomic status. Low control predicted absence due to back pain, independently of other work characteristics. Low pace tended to be associated with absence due to back pain. The effects of work characteristics, in magnitude and direction, differed by gender and socioeconomic status; such interactions should be investigated in other studies. The psychosocial work environment represents a potentially reversible cause of ill health.

\section{Acknowledgments}

We thank all the participating civil service departments and their welfare, personnel and establishment officers; the Civil Service Occupational Health Service: Dr Elizabeth McCloy, Dr George Sorrie and Dr Adrian Semmence; the Civil Service Central Monitoring Service and Dr Frank O'Hara; the Council of Civil Service Unions 
and all participating civil servants. We would like to thank all members of the Whitehall II study team, and in particular Jenny Head and Alan Harding for their computer support.

The study was supported by grants from the Institute for Work and Health, Toronto, Ontario, Canada, and the Volvo Research Foundation, Sweden; the Medical Research Council; the Health and Safety Executive; the British Heart Foundation; the National Heart Lung and Blood Institute (2RO1 HL36310); the Agency for Health Care Policy and Research (5 RO1 HS06516); the New England Medical Centre-Division of Health Improvement; and the John D and Catherine T MacArthur Foundation Research Network on Successful Midlife Development. Michael Marmot was supported by a research professorship from the British Medical Council.

\section{References}

1. Klaukka T, Sievers K, Takala J. Epidemiology of rheumatic diseases in Finland in 1964-76. Scand J Rheumatol 1982;47 suppl:5-13.

2. Volinn E. Theories of back pain and health care utilisation. Neurosurg Clin North Am 1991;2:739 - 47.

3. Logan WPD, Cushion AA. Morbidity statistics from general practice; vol I (General: general register office). London: Her Majesty's Stationery Office, 1958. Studies on medical and population subjects, no 14.

4. Royal College of General Practitioners. Morbidity statistics from general practice: second national study 1970-1. London: Her Majesty's Stationery Office; 1974. Studies on medical and population subjects, no 26 .

5. Royal College of General Practitioners/OPCS/Dept of Health and Social Security. Morbidity statistics from general practice: third national study, 1981-82. London: Her Majesty's Stationery Office; 1986. Series MB5.

6. OPCS Monitor. Morbidity statistics from general practice 1991-1992. OPCS Monitor, 1994. MB5

7. Clinical Standards Advisory Group. Epidemiology review: the epidemiology and cost of back pain. London: Her Majesty's Stationery Office, 1994.

8. Waddell G. Biopsychosocial analysis of low back pain. Ballieres Clin Rheumatol 1992;6:523-57.

9. Nachemson A. Newest knowledge of low back pain. Clin Orthop 1992;8-20.

10. Office of Population Censuses and Surveys, Martin J, Meltzer $\mathrm{H}$, Elliot D. OPCS surveys of disability in Great Britain; report 1 (The prevalence of disability among adults). London: Her Majesty's Stationery Office 1988;

11. Spitzer WO, LeBlanc FE, Dupuis M. Scientific approach to the assessment and management of activity related spinal disorders: a monograph for clinicians: report of the Quebec Task Force on Spinal Disorders. Spine 1987;12(7S):1—59.

12. Frank JW, Pulcins IR, Kerr MS, Shannon HS, Stansfeld SA. Occupational back pain - an unhelpful polemic [review]. Scand J Work Environ Health 1995;21:3-14.

13. Skovron M. Epidemiology of low back pain. Ballieres Clin Rheumatol 1992;6:559-73.

14. Walsh K, Varnes N, Osmond C, Styles R, Coggon D. Occupa- tional causes of low-back pain. Scand J Work Environ Health 1989;15:54—9.

15. Deyo R, Rainville J, Kent D. What can the history and physical examination tell us about low back pain? JAMA 1992;268:760-5.

16. Jensen MC, Brant-Zawadzki MN, Obuchowski N, Modic MT, Malkasian D, Ross IS. Magnetic resonance imaging of the lumbar spine in people without back pain. $N$ Engl J Med 1994:331:69-73.

17. Organization for Economic Co-operation and Development (OECD). The OECD employment outlook. Paris: OECD, 1991.

18. Lloyd M, Gauld S, Soutar C. Epidemiologic study of back pain in miners and office workers. Spine 1986;11:136 - 40

19. Andersson GBJ. Frymoyer JW, editors. The adult spine: principles and practice. New York (NY): Raven Press, 1991.

20. Reisbord L, Greenland S. Factors associated with sel-reported back pain prevalence: a population based study. J Chronic Dis 1985;38:691-702.

21. Croft PR, Rigby AS. Socioeconomic influences on back problems in the community in Britain. J Epidemiol Community Health 1994:48:166-70.

22. Marmot MG, Bobak M, Davey Smith G. Explanations for social inequalities in health. In: Amick BC, Levine S, Tarloy AR, Chapman Walsh D, editors. Society \& health. New York/ Oxford: Oxford University Press, 1995.

23. Bigos S, Battić M, Spengler D, Fisher L, Fordyce W, Hansson $\mathrm{T}$, et al. A prospective study of work perceptions and psychosocial factors affecting the report of back injury. Spine $1991 ; 16: 1-6$

24. Bongers PM, de Winter CR, Kompier MAJ, Hildebrandt VH. Psychosocial factors at work and musculoskeletal disease [review]. Scand J Work Environ Health 1993;19:297-312.

25. Marmot MG, Davey Smith G, Stansfeld S, Patel C, North F, Head J, et al. Health inequalities among British Civil Servants: the Whitehall II study. Lancet 1991;337:1387_-93.

26. Office Population Censuses and Surveys. General household survey 1977. London: Her Majesty's Stationary Office, 1979.

27. Karasek R, Baker D, Marxer F, Ahlbom A, Theorell T. Job decision latitude, job demands and cardiovascular disease: a prospective study of Swedish men. Am J Public Health 1981; 71:694-705.

28. Rose G, Blackburn H, Gillum RF. Cardiovascular survey methods. 2nd ed. Geneva: World Health Organization, 1982.

29. North F, Syme SL, Feeney A, Head J, Shipley MJ, Marmot MG. Explaining socioeconomic differences in sickness absence: the Whitehall II study. BMJ 1993;306:361—6.

30. Numerical algorithims Group. The GLIM system release 3.77; manual. 2nd ed. Oxford: Numerical Algorithims Group, 1987.

31. Bosma HJ, Marmot MG, Hemingway H, Nicholson A, Brunner EJ, Stansfeld SA. Low job control and the risk of coronary heart disease in the Whitehall II study. BMJ. In press.

32. Leino P. Symptoms of stress predict musculoskeletal disorders. J Epidemiol Community Health 1989;43:293-300.

33. Leino P, Magni G. Depressive and distress symptoms as predictors of low back pain, neck shoulder pain, and other musculoskeletal morbidity: a 10 year follow up of metal industry employees. Pain 1993;53:89—94.

34. Theorell T, Harms-Ringdahl K, Ahlberg-Hulten G, Westin B. Psychosocial job factors and symptoms from the locomotor system - a multicausal analysis. Scand J Rehabil Med 1991; $23: 165-73$.

35. Houtman ILD, Bongers PM, Smulders PGW, Kompier MAJ. Psychosocial stressors at work and musculoskeletal problems. 
Scand J Work Environ Health 1994;20:139_-45.

36. Rael EGS, Stansfeld SA, Shipley M, Head J, Feeney A, Marmot $\mathrm{M}$. The role of social support and poverty-related problems as predictors of sickness absence in Whitehall II study. J Epidemiol Community Public Health 1995;49:474-81.

37. North FM, Syme SL, Feeney A, Shipley M, Marmot M. Psychosocial work environment and sickness absence among British civil servants: the Whitehall II study. Am J Public Health 1996;86:332 - 40.

38. Stansfeld SA, Rael EGS, Head J, Shipley M, Marmot M. Social support and psychiatric sickness absence: a prospective study of British civil servants. Psychol Med. In press.

39. Marmot MG, Feeney A, Shipley M, North F, Syme SL. Sickness absence as a measure of health status and functioning: from the UK Whitehall II Study. J Epidemiol Community Health 1995;49:124-30.

40. Jackson S. Participation in decision making as a strategy for reducing job-related strain. J Appl Psychol 1983;68:3-19.

Received for publication: 27 May 1996 